\title{
INEQUALITIES INVOLVING GENERALIZED TRIGONOMETRIC AND HYPERBOLIC FUNCTIONS
}

\author{
EDWARD NEUMAN
}

Abstract. The Huygens-Wilker type inequalities involving generalized trigonometric functions and generalized hyperbolic functions are established. The first and the second inequalities of Huygens and Wilker, for classes of functions under discussion, are also investigated.

Mathematics subject classification (2010): 26D07, 26D15.

Keywords and phrases: Generalized trigonometric functions, generalized hyperbolic functions, HuygensWilker type inequalities, Huygens inequalities, Wilker inequalities, inverse functions.

\section{REFERENCES}

[1] A. BARICZ, B. A. BHAYO, R. KLÉN, Convexity properties of generalized trigonometric and hyperbolic functions, Aequat. Math. (2013), doi:10.1007/s00010-013-0222-x.

[2] B. A. BHAYO, Power mean inequality of generalized trigonometric functions, preprint.

[3] B. A. BHAYO, M. VUORINEN, Inequalities for eigenfunctions of the $p$-Laplacian, Issues of Analysis 2 (20) (2013), No. 1, 13-35.

[4] B. A. Bhayo, M. Vuorinen, On generalized trigonometric functions with two parameters, J. Approx. Theory 164 (2012), No. 10, 1415-1426.

[5] B.-N. GuO, B.-M. QIAO, F. QI, AND W. LI, On new proofs of Wilker inequalities involving trigonometric functions, Math. Inequal. Appl. 6 (2003), No. 1, 19-22.

[6] C. Huygens, Oeuvres Completes 1888-1940, Société Hollondaise des Science, Haga.

[7] W.-D. JiAng, M.-K. WANG, Y.-M. ChU, Y.-P. JiAnG, F. QI, Convexity of the generalized sine function and the generalized hyperbolic sine function, J. Approx. Theory 174 (2013), 1-9.

[8] R. KlÉN, M. VUORINEN, X. ZHANG, Inequalities for the generalized trigonometric and hyperbolic functions, J. Math. Anal. Appl. 409 (2014), 521-529.

[9] P. LindQvist, Some remarkable sine and cosine functions, Ricerche di Matematica 44 (1995), No. 2, 269-290.

[10] E. Neuman, One- and two- sided inequalities for Jacobian elliptic functions and related results, Integral Transforms Spec. Funct. 21 (2010), No. 6, 399-407.

[11] E. Neuman, On Wilker and Huygens type inequalities, Math. Inequal. Appl. 15 (2012), No. 6, $271-$ 279.

[12] E. Neuman, Inequalities for weighted sums of powers and their applications, Math. Inequal. Appl. 24 (2012), No. 4, 995-1005.

[13] E. Neuman, On Gauss lemniscate functions and lemniscatic mean II, Math. Pannon. 23 (2012), No. $1,65-73$.

[14] E. Neuman, On lemniscate functions, Integral Transforms Spec. Funct. 15 (2013), No. 3, 164-171.

[15] E. Neuman, Wilker-and Huygens- type inequalities for Jacobian elliptic and theta functions, Integral Transforms Spec. Funct. 23 (2013), No. 12, 976-981.

[16] E. Neuman, Wilker- and Huygens- type inequalities for some elementary functions and Eulerian numbers, Adv. Studies Contemp. Math., in press.

[17] E. NEUMAn, J. SÁNDOR, On some inequalities involving trigonometric and hyperbolic functions with emphasis on the Cusa-Huygens, Wilker and Huygens inequalities, Math. Inequal. Appl. 13 (2010), No. $4,715-723$. 
[18] S. TAKEUCHI, Generalized Jacobian elliptic functions and their application to bifurcation problems associated with p-Laplacian, J. Math. Anal. Appl. 385 (2012), 24-35.

[19] S. TAKEUCHI, The basis property of generalized Jacobian elliptic functions, arXiv math.CA $1310.0597 \mathrm{v} 1$.

[20] J. B. Wilker, Problem E 3306, Amer. Math. Monthly 96 (1989), 55.

[21] S.-H. WU AND H. M. SRIVASTAVA, A weighted and exponential generalization of Wilker's inequality and its applications, Integral Transforms Spec. Funct. 18 (2007), No. 8, 525-535.

[22] S.-H. Wu AND H. M. SRIVASTAVA, A further refinement of Wilker's inequality, Integral Transforms Spec. Funct. 19 (2008), No. 10, 757-765.

[23] Li Yin, Li-Guo HuAng, Some inequalities for the generalized sine and the generalized hyperbolic sine, J. Classical Anal. 3 (2013), No. 1, 85-90.

[24] L. ZHU, A new simple proof of Wilker's inequality, Math. Inequal. Appl., 8 (2005), No. 4, 749-750.

[25] L. ZHu, On Wilker-type inequalities, Math. Inequal. Appl. 10 (2007), No. 4, 727-731.

[26] L. ZHU, Some new Wilker type inequalities for circular and hyperbolic functions, Abstract Appl. Analysis, Vol. 2009, Article ID 485842, 9 pages. 